\title{
Considerações Sôbre o Cadastro de Pessoal com Vista ao Plano de Salário e com Base na Experiência Norte-Americana
}

RAIMUNDO XAVIER DE MENEZES

Técnico de Administração

\section{O PAPEL DO CADASTRO}

Tal como ocorre usualmente em relação a muitas outras atividades, é sobremodo relevante o papel do cadastro em matéria de administração de pessoal. Quanto maior e mais complexa fôr a companhia ou organização envolvida nesse problema, tanto mais verdadeira se torna a afirmação.

Com efeito, em uma organização pequena, com poucas pessoas arroladas na fôlha de pagamento, o chefe de pessoal pode acompanhar as mudanças e, se necessário, colhêr dados concretos requeridos pela administração de pessoal da emprê$\mathrm{sa}$, sem precisar manter certos arquivos ou compilar registros vários. Numa situação dessa ordem, torna-se também dispensável o uso de fichas ou modelos padronizados.

Em se tratando, porém, de organização de maior vulto, pode-se afirmar com veemência que sua direção não poderá chegar a bom têrmo, se não se utilizar cabalmente das vantagens que a técnica cadastral the pode proporcionar.

É oportuno notar que neste campo de conhecimentos existem hoje sistemas extremamente simples e outros minuciosamente elaborados, para adequar-se aos requisitos das necessidades mais diversificadas existentes na prática. Em face das limitações de espaço, e também de utilização em nosso ambiente, preferimos ficar no meio têrmo, num ponto em que se possa alcançar maior margem de proveito efetivo dos ensinamentos ora sumarizados. 


\section{O CADASTRO NA AREA SALARIAL}

Pelas suas vinculações com as demais fases do programa de pessoal, o problema da retribuição é de grande importância na coleta de informações e manutenção de registros. Essa circunstância dá ensejo a que dispensemos relêvo especial a êsse tópico, conseguindo, assim, facilitar o entendimento do assunto.

Não é singular, como tem sido reiteradamente repetido, o processo referente à administração de salário. Com efeito, muitas atividades, motivadas pelo mesmo propósito, são entre si combinadas, constituindo-se finalmente numa seqüência de operações, que visam, na totalidade, à efetivação da política ou do programa de administração de salário da instituição.

Assim sendo, êsse programa pode variar de companhia para companhia, tal como nos adverte R. W. Ells no prefácio de seu livro Salary and Wage Administration, quando afirma:

"a administração de salário é um campo onde cada emprêsa opera em bases diferentes, não havendo, portanto, um modêlo padrão a seguir."

Entre outros Lionel B. Michael defende ponto de vista idêntico. No seu livro Wage and Salary Fundamentals and Procedures, às páginas 291, êle sustenta:

"De igual modo, é difícil, se não impossível, tentarmos prescrever um conjunto de métodos capaz de aplicar-se arbitràriamente a tôda e qualquer situação individual. Evidentemente cada tentativa nesse sentido, não seria apenas fútil como irrealística, uma vez que os métodos a utilizar variam substancialmente, dependendo da companhia em si, sua política de administração, as relações sindicais e o grau e a extensão em que seu dirigente desejar prosseguir formalizando, pondo em prática e mantendo procedimentos e métodos específicos."

A despeito dessa variedade no tocante a políticas e programas, há contudo linhas gerais de comportamento a que obedecem inevitàvelmente as atividades concernentes à administração de salários.

Pode-se dizer que, de modo geral, três fatôres básicos controlam sempre todo programa de administração de salários. São êles: o trabalho a executar, o trabalhador e as condições ambientais. E o que ensinam Smyth e Murphy no seu livro Job 
Evaluation and Employee Rating quando diz que, ao cogitar-se da retribuição do trabalho, deve-se levar em consideração:

1) a natureza do trabalho a executar;

2) o valor corrente competitivo do tipo dêsse trabalho dentro da comunidade ou no ramo industrial; e

3) a eficiência com que o trabalho é executado.

Para a devida consideração dêsses fatôres impõe-se a divisão do programa de administração de salários em três partes distintas, quais sejam: avaliação do trabalho ou classificação de cargos; fixação do salário; e apuração de mérito. Cada uma dessas partes requer um conjunto particular de registros, isto é, um cadastro especial.

Já que não há um programa de administração de salários padronizado, como se esclareceu acima, capaz de adaptar-se a tôda e qualquer organização, torna-se impossivel determinar, a priori, de modo preciso, as espécies ou tipos de registros usados nas atividades de execução de política salarial. Leonard W. Ferguson, contudo, relacionou, certa vez, uma série de itens destinados a servir de guia na solução dêsse problema.

Acha êle que em matéria de administração de salários cada emprêsa deve manter registros que a qualquer tempo possam espelhar:

a) as descrições de cargos;

b) a classificação dos cargos;

c) os padrões ou faixas de salário;

d) as disposições do plano de pagamento sôbre fixação e ajustamento salarial;

e) a data de início de aplicação do plano; e

f) o nome de cada empregado que receba ajustamento salarial, juntamente com (1) a data de admissão, (2) a data e o motivo da concessão do ajustamento, (3) a respectiva classificação e (4) os valôres salariais imediatamente anterior e posterior a cada ajustamento.

Afirma êle que "tôda emprêsa possuidora de registros de tal natureza estará em condiçôes de a qualquer época saber:

a) a data em que cada escala de salário foi estabelecida;

b) os cargos representados a qualquer tempo;

c) o número de empregados em cada classe a qualquer tempo;

d) as taxas máxima e mínima de salário despendido com qualquer cargo a qualquer tempo; 
e) o número e percentagem de empregados em cada faixa compreendida entre aquelas taxas, com os aumentos e decréscimos concedidos num certo período de retribuição;

f) as razões dêsses aumentos ou decréscimos, mostrando o número devido a promoção, transferência, reclassificação, deslocamento no nivel, mérito, tempo de serviço ou outra razão especificada;

g) o procedimento seguido na efetivação dêsses aumentos ou decréscimos e por quem foram originàriamente autorizados; e

h) o salário médio pago em cada faixa por período de retribuição.

"Qualquer emprêsa", assegura êle, "que mantenha tais registros estará sempre em condições de saber ou determinar (em comparando dois períodos de retribuição entre si) se os aumentos ou decréscimos de salário foram efetivados com maior ou menor freqüência, em total maior ou menor, em percentagem superior ou inferior, ou numa mais ampla ou restrita proporção de empregados durante um período em confronto com qualquer dos demais. Tal emprêsa estará apta também a determinar se o acréscimo ou decréscimo percentual, durante dado período de retribuição, no salário médio de certa faixa foi supepior, inferior ou igual ao verificado em qualquer outro período de retribuição."

Nesta análise o autor está interessado mais no trabalho burocrático. Evidentemente numa fábrica outras espécies de registros devem existir, como seja para fazer face aos problemas de ordem gerencial. Contudo, o quadro reproduzido é bastante compreensivo e pode constituir-se guia útil no estabelecimento de um efetivo sistema cadastral para fins de administração de salário.

\section{ALGUNS EXEMPLOS NO MEIO EMPRESARIAL}

É crescente a ênfase dada aos registros de pessoal em geral, e especialmente no que tange a administração de salários, no comércio e na indústria privada. Nos Estados Unidos, por exemplo, de há muito que sistemas bem engendrados foram postos em prática e vêm sendo aperfeiçoados persistentemente. Tôdas as emprêsas especializadas no gênero estão hoje apareIhadas para instruir ou ajudar organizações grandes, médias ou pequenas no tocante a procedimentos e solução de problemas de tal natureza, aplicando instrumentalidade adequada desde arquivos manuais simples até sistemas complicados de computação eletrônica. 
O objetivo primacial a considerar é a obtenção de resposta a indagações importantes com respeito a cada tópico, já existindo modelos padronizados para servir em qualquer fase da administração de pessoal, seja em matéria de fichas, seja em matéria de arquivos, para uso manual, mecânico ou eletrônico, de acôrdo com a situação real confrontada.

Nesse particular, adaptando-se ao procedimento utilizado, são marcos fundamentais que não podem deixar de ser levados em conta, não importa o tamanho da emprêsa, caso haja o propósito de efetuar-se uma administração de pessoal em têrmos racionais:

a) a ficha de admissão onde registra-se, geralmente, o primeiro contacto do candidato com a organização. Naturalmente deve-se prever aí a possibilidade de conseguir-se resposta a múltiplas questões que ensejem o julgamento acurado da capacidade do candidato. $\mathrm{O}$ formulário deve ser simples, se bem que suficientemente completo, de modo que abranja todos os fatos com reflexos na futura vida funcional do empregado;

b) o fichário de candidaturas em que a ficha de admissão deve ficar permanentemente arquivada e pronta para qualquer futura referência. Com ela, na pasta de admissão, devem ser guardadas intactas tôda correspondência confidencial, cartas de recomendação e as provas ou exames de capacidade prestados;

c) dados sôbre o cargo requeridos para o efetivo funcionamento da emprêsa convenientemente especificados devem constar de arquivo. Tais registros devem compreender uma análise detalhada do trabalho executado, as qualificações exigidas do empregado e uma avaliação criteriosa que permita o estabelecimento de limites mínimo e máximo de retribuição;

d) fichas de registro operacional onde devem figurar as ocorrências significativas com respeito a tôdas as atividades, atos e decisões concernentes a qualquer das fases de administração de pessoal;

e) dados sôbre o empregado registrados de modo conciso, mas suficientemente abrangentes, com respeito ao grupo ativo, oferecendo um inventário perpétuo das atitudes, habilidades e realizações de cada um constituem elementos essenciais de um bem organizado Departamento de Pessoal. Daí pode-se extrair dados indispensáveis para o preenchimento de vagas, para a efetua- 
ção de promoções, para a concessão de aumentos salariais, bem como para atender reivindicações de caráter urgente e impositivo;

f) fichário histórico do empregado, suplementando os dados sôbre o empregado, compreende uma pasta onde as cópias de tôdas as fichas de registro operacional pertencentes ao empregado devem ficar permanentemente arquivadas para pronta utilização e fornecimento de informações substanciais em que se devam basear as atividades subseqüentes de supervisão. Também se pode a êle recorrer no esclarecimento de ações adotadas em relação ao empregado;

g) fichário com referência cruzada, onde os empregados são relacionados alfabèticamente pelo nome, por lotação, por antigüidade, pelo mérito apurado e pela natureza do trabalho executado, é extremamente necessário à consecução de informes completos sôbre o empregado em qualquer espécie de classificação. Esse fichário não só simplifica o trabalho do Diretor de Pessoal como faz economizar e ganhar tempo na coleção de dados sôbre pessoal, completamente atualizados.

Sôbre êste assunto há copioso número de formulários e sistemas de arquivo que podem ser adaptados às mais diversas situações e realidades, cobrindo a vida funcional desde o recrutamento até a aposentadoria. Entre os mais usados figuram aquêles relacionados com o registro de fatos e circunstâncias atinentes a: recrutamento e seleção, admissão, requisição de empregados, especificações de cargos, exames médicos, identificação, histórico funcional, dados sôbre o cargo, faltas e acidentes, dados para pronto-socorro, dados para comunicação, avaliação de mérito, treinamento recebido, pontualidade, referência cruzada sôbre os registros do empregado, ordenação pelo tempo de serviço, dados financeiros, conclusão da atividade e arquivo histórico do empregado.

Considerados devidamente no estabelecimento de um sistema de registros funcionais todos êsses itens, o corpo dirigente da emprêsa poderá, fàcilmente, ter a resposta correta para as questões determinadas pela natureza de sua responsabilidade na área da administração de salários.

\section{A EXPERIENCIA AMERICANA NA AREA FEDERAL}

O Sistema de cadastro para efeito de administração de pessoal do Govêrno Federal norte-americano, destinado a atender inclusive as exigências do plano de pagamento do funcionalis- 
mo, esteia-se no "Federal Personnel Manual" e no "Civil Service Handbook", ambos editados pela "Civil Service Commission". Foi prescrita a manutenção de apenas um conjunto básico de registros, uma vez que a estrutura dos órgãos de pessoal variam em função da amplitude da repartição, do programa a executar, da localização ou outro fator significativo superveniente. Dêsse modo, o objetivo do sistema foi estabelecer uma moldura na qual as situações diferentes possam enquadrar-se e não talhar um figurino rígido e inadaptável.

O sistema fundamentou-se no propósito de oferecer aos órgãos ou setores de pessoal a seguinte instrumentalidade:

a) um registro atualizado e compreensivo da atividade, status, capacidade e outros elementos significativos do histórico funcional de cada empregado;

b) um contrôle sôbre os cargos, preenchidos ou vagos, com previsão orçamentária e segundo a lotação;

c) um contrôle dos atos pendentes no órgão de pessoal;

d) um fichário com sinalização para acompanhar as requeridas alterações funcionais;

e) dados básicos para o preparo e verificação de relatórios de pessoal, dados para estatísticas de mensuração do trabalho e para inspeção sôbre atos de pessoal efetivados durante qualquer período;

f) dados básicos necessários à manutenção de registros sôbre pessoal disponível;

g) fichário dos empregados em ordem alfabética e por lotação.

A manutenção de registros passou a ser considerada em dois grupos: registros e fichários pertinentes ao órgão de pessoal; idem pertinentes aos órgãos operacionais. cuidar:

De acôrdo com o regulamento, o órgão de pessoal deve

a) do cartão de registro do serviço;

b) da fôlha de identificação do cargo;

c) das modificações de situação funcional;

d) da descrição de cargo;

e) dos registros oficiais de tudo que tenha reflexo no status ou nas atribuições do empregado. 
Para tanto impõe-se manter o seguinte sistema de registros:

a) arquivo de contrôle do serviço;

b) arquivo cronológico das notificações sôbre atos funcionais;

c) arquivo de descrições de cargos;

d) arquivo de pastas de assentamentos individuais.

$O$ arquivo de contrôle do serviço consiste de: (1) fôlhas de identificação do cargo; (2) cartões de registros de serviço; (3) cartões divisórios identificadores dos vários seguimentos organizacionais.

O arquivo cronológico das notificações sôbre atos funcionais contém não só cópias das notificações sôbre atos funcionais, como também um apanhado cronológico diário das ocorrências relacionadas com o empregado.

tes partes:

$\mathrm{O}$ arquivo de descrições de cargos compõe-se das seguin-

a) arquivo vivo: êste arquivo contém apenas uma cópia da descrição de cada cargo classificado. Descrições de cargos adicionais não são consideradas necessárias. Devese, porém, indicar na descrição o número de cargos adicionais idênticos autorizados. Se os cargos adicionais idênticos existem em setor organizacional diferente daquele do cargo básico deve-se fazer na descrição arquivada uma conveniente referência cruzada;

b) arquivo morto: neste arquivo deve encontrar-se uma cópia apenas da descrição de cada cargo abolido.

0 arquivo de pastas de assentamentos individuais reúne para cada empregado os documentos oficiais que lhe dizem respeito.

Ao nivel operacional os registros individuais dos empregados restringem-se a:

a) cartão de registro do empregado;

b) fôlha de identificação do cargo; e

c) um arquivo de descrições de cargos.

0 arquivo de descrições de cargos ao nível operacional deve conter uma cópia da descrição de cargo com referência a:

a) cada cargo incluído no orçamento;

b) cada cargo inativo, isto é, cargos sem ocupante e sem dotação orçamentária, cuja extinção não se recomenda em virtude da possibilidade de a êles recorrer-se em futuro previsível. 
É aconselhável que as descrições de cargos idênticos adicionais não figurem nesse arquivo.

Tanto o "Manual" quanto o "Handbook" citados previram muitos outros detalhes quanto à estrutura e funcionamento do sistema. Com respeito a cada item êles fornecem explicações sôbre o propósito, localização, disposição etc., com o fito de evitar incompreensões e enganos e dar orientação quanto a organização do sistema em cada repartição.

Além dêsses registros básicos recomendados para todo o serviço público federal, admite-se a existência de outros em certas repartições para atender exigências motivadas por peculiaridades especiais.

Como ficou acima assinalado, o programa de administração salarial varia de emprêsa para emprêsa e muito mais entre o comércio, a indústria e o serviço público. Assim sendo, não se pode esperar uniformidade de tratamento do problema nem no todo, nem na parte referente à manutenção de registros. Comumente, em cada instituição o responsável pelo problema vê-se obrigado a enfrentar a realidade e, consentâneamente com seu programa, ajustar a estrutura e o funcionamento dêsse arcabouço de sistema ao seu caso específico, obtendo em conseqüência um corpo de normas próprias que passam a constituir seu Manual, em cujo âmbito de jurisdição se torna a verdade que não pode ser desobedecida. 
